\title{
Neuro-fuzzy assessment of pupil performance based on e-learning platform implementation
}

\author{
Dalibor Petkovicí, ${ }^{1,}$, Nebojša Denić ${ }^{2}$ \\ ${ }^{1}$ University of Niš, Pedagogical Faculty in Vranje, Partizanska 14, 17500 Vranje, Serbia \\ Email: dalibortc@gmail.com \\ ${ }^{2}$ University of Priština, Faculty of Science and mathematics, Ive Lole Ribara 29, 38220 \\ Kosovska Mitrovica Serbia \\ Email: nebojsa.denic@alfa.edu.rs \\ *Corresponding author
}

How to cite this paper: Dalibor Petković, Nebojša Denić (2020) Neuro-fuzzy assessment of pupil performance based on e-learning platform implementation. Journal of the Institute of Electronics and Computer, 2 ,

12-27. https://doi.org/10.33969/JIEC.2020.21 $\underline{002}$

Received: November 5, 2019

Accepted: January 13, 2020

Published: January 20, 2020

Copyright (C) 2020 by author(s) and Institute of Electronics and Computer.

This work is licensed under the Creative

Commons Attribution International

License (CC BY 4.0).

http://creativecommons.org/licenses/by/4.0/

\section{Open Access}

\begin{abstract}
Learning and teaching process for the both, learners and teachers, could be challenging task since every learner has different cognitive preconditions. Hence every learner should have different learning material and different learning paths in order to achieve given learning goals. In this article was made an e-learning platform for teacher and learners based on object-oriented approach. In the platform every learner could has personalized learning contents based on the learners' background. The personalized learning contents could be achieved by different learning paths for each learner. Object-oriented technique by unified modelling language (UML) was performed for the modelling process of the learning platform. Afterwards the pupil performance was analyzed after the introduction of the e-learning platform by computational intelligence approach.
\end{abstract}

Keywords

Pupils; e-learning; computational; intelligent; mathematics

\section{Introduction}

Learning process could be complex task for many learners which depend on their cognitive preconditions. The process requires a lot of effort from many students to achieve desired learning goals. One of the main problems could be motivation for learning new materials and new knowledge. Also learning level could be different for all learners which depend on their background. E-learning has potential to improve learners' learning motivation and to improve their cognitive abilities.

One of the most important aspects of introduction of e-learning platform in education system is rapid increasing of information, computing and 
telecommunication technology. This leads to the different uses of the electronic multimedia which is suitable for improving of learning process. The multimedia tools could have high impact on education based on learners' motivation for learning. The learning process is becoming more user friendly in e-learning system. On one hand the e-learning offers removing of barriers in the learning process which means the learners could access to a course by internet connection in any time and space. Also learning process could be monitored by teachers constantly.

Relatively little research has examined the links between pupils performances and other influential factors. Pupil performances could be influential by several factors. Each of the factors could have different impact on the pupil performance. To identify which factor has the strongest impact on the pupil performance there are need for more comprehensive investigations. So far there are several investigations which analyze teaching quality and pupil performances.

In study [1] was assessed the extent to which nine elementary physical education teachers implemented the quality of teaching practices where each of the nine teachers demonstrated different quality levels in terms of the four essential dimensions of the teaching practices. Teaching process is challenging process due to complex and abstract nature, especially in mathematics [2]. There is need for training and information the e-learning domain [3]. In article [4] was reported efforts to embed quality teaching in a local urban primary school in the north of England, under pressure from the Local Authority to raise standards where the social realities of the Year 3 classroom, and the research evidence, all point to recognition that official versions of 'quality teaching' are not enough to improve student learning outcomes. In paper [5] was discussed the implications of the research for classroom practice and suggests that, as creativity is a complex, multi-faceted concept and process, the theoretical three-feature model and related criteria evolved in the study provides a sound framework to explore creativity within an educational context. In paper [6] was explored the challenges facing educators in a time when modern technology, and especially modern social technology, has an increasingly powerful hold on our lives. The relationship between school reforms, specifically those involving the introduction of new school types, and pupil performance was studied in article [7]. Functional and organizational characteristics of teaching model of pupils' research competence formation in the context of humanitarian subject-oriented classes of general education schools were taken into consideration in article [8] where the research activity aimed at increasing the educational process quality in general education school is one of the productive ways of pupils' research competence formation. In paper [9] was analyzed to what extent pupils value the characteristics of the state school foodservice and identify which variables affect the degree of pupils' satisfaction with the quality of school meals. Findings in article [10] could reinforce the need for research on the negative motivational pathways which link controlling teaching to poor quality student motivation. In paper [11] were employed techniques of multilevel modelling and geographical information systems (GIS) to identify factors affecting pupil performance in primary education 
of Malawi. The study reveals that in some districts pupils performed much better than others. Research [12] was aimed at improving the quality of standard four pupils' response in science inquiry teaching using Easy Erase Response Board (EERB). Researchers found out that the quality of pupils' in-class response was very low. They also exhibited a passive attitude in answering questions in inquiry teaching. How teaching quality impacts students' outcomes in public and low fee charging private schools in India was investigated in paper [13]. Factors affecting school performance are: students' quality, teachers' quality (their ability and the quality of work life) and the way they are motivated, the Principal's leadership style, and the schools' physical working conditions [14].Factors that increase students' adoption of learning games have been widely studied in past; however, the effect of these factors on learners' performance is yet to be explored. Results in article [15] suggested that there are attitudinal factors affecting knowledge acquisition gained by a game. Study [16] was investigated the use of general mathematical strategies by pupils of junior high school age. Main effects were found for cognitive level, year level, and sex. The sex effects are in contrast with similar effects from most other mathematical studies in that girls outperformed boys at each year level. In study [17] authors employed a multilevel analysis procedure to examine the key pupil- and school-level factors that influenced reading and mathematics achievement among Grade 5 primary school pupils in Laos. From the results of the analyses, several policy suggestions have been made to improve the facets of education that seem to be worthy of action.

E-learning web environments are increasingly being used to provide cognitive training [18]. E-book learning platforms are increasingly used as curriculum resources for independent reading at school and home [19]. In recent years, online courses have emerged as a new way to educate students in distance learning settings. However, as the demand increases, educational institutions are facing the challenge of how to prove that online students are who they claim to be during e-learning activities, especially exams [20]. In paper [21] was described an experience in using e-learning platforms to support face to face instruction in academic field. In paper [22] was described how the educational process may be improved and students may be motivated to do homework tasks and to attend classes in higher education and the main highlights lies in importance of using collaborative e-learning platforms in higher education to support face to face teaching. In paper [23] was presented a study about using e-learning platform in university teaching process. The Moodle platform, which was proposed and initially developed by Martin Dougiamas, improves the didactic process by helping professors to generate and publish online content [24]. However in e-learning platforms there are many important elements that must be taken into account: authentication, access control, data integrity, content protection, etc. Information security can be obtained using methods such as cryptography and network protocols [25]. The medium of e-learning has achieved advancement in various fields such as adaptive e-learning systems [26]. Implementation of an adaptive and 
Dalibor Petković et al.

personalized e-Learning system which is based on open source software and technologies was propose in article [27].

Based on the previous research in this study the main aim is to make a general framework of the e-learning platform based on different preconditions and background of learners. Object oriented approach [28, 29] is used by unified modelling language [UML] [30]. Object-oriented strategy could encapsulate data and process into thing called objects. Then relationships and interactions between the objects should be determined through UML. By this way one can visualize the system architecture and dynamical interactions between the objects could be shown as well. Afterwards the pupil performance is analyzed after e-learning platform implementation by computational intelligence approach. ANFIS (Adaptive neuro-fuzzy inference system) [31] is used to estimate which factors are the most important for the pupil performance of mathematics based on educational software implementation.

\section{Data and Methodology}

\subsection{E-learning platform}

E-learning process has usually two sections. One section is for communication purposes and the second section is for learning of learning material and contents. All of the activities need one platform in order to maintain administrative tasks of the learning process, to document and deliver the learning material and to enable course enrolling of the learners with different learning paths.

Each learner has different learning characteristics which depend on learning style, background and profile. Therefore each learner should have possibility to create his/her own learning path. It means the learning path should not be generalized for all learners but it should be adaptable. For such a purposes there is need to develop an information system which will support it. The information system should have capabilities for planning of different learning paths and monitoring of the learning progress.

\subsection{Modelling of E-learning platform}

Modelling of e-learning platform could be very complicated process because of many parameters and factors. For example there are subjects and processes which need to be identified and modelled in the system. Identification of the subjects and processes is not easy task. One way to simplify the modelling of e-learning platform is to model each function of the system separately and finally to merge them. There is need to include different technical and business aspects during modelling of e-learning platform. In other words one needs to identify which business process needs to improve by the e-learning platform. Here in the article the main goal is to improve educational process in education system. 
Rational unified process (RUP) [32] is implemented for the modeling process of the platform. The RUP is based on Unified Modelling Language (UML).Figure 1 shows the RUP methodology elements.

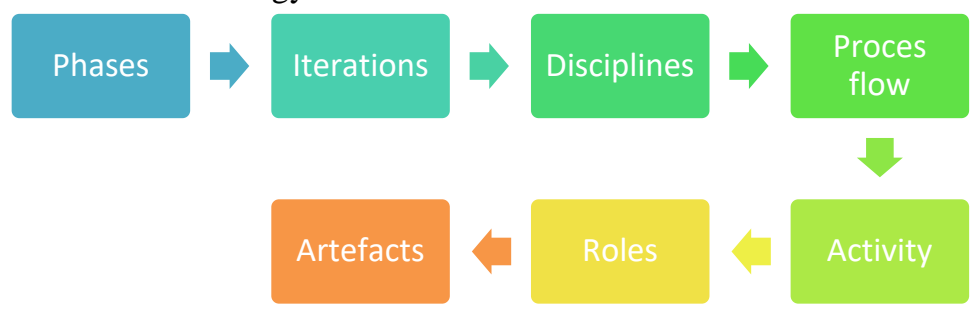

Figure 1. RUP methodology elements

Figure 2 shoed four phases of the RUP methodology (Figure 2). The most important phase is the first phase or inception where one need to identify understand the system vision and requirements. In the phase one needs to identify systems actors or users and use cases of the users.

Inception

\section{Elaboration}

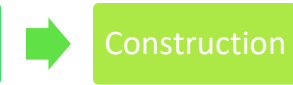

\section{Transition}

Figure 2. Phased of the RUP methodology

\subsection{Data and hypothesis}

Data in this study is based on mathematics lecture in basic school. Statistical data and questionnaire study is used for data generation. Data is collected during three last school years from grade V, through grade VI and beginning of grade VII.

The main goal of the study is determination of e-learning influence of adopted knowledge continuity in mathematics according to initial test results. Data is divided in two groups, experimental and control group (Tables 1 and 2). Experimental group includes e-learning while control group includes traditional learning without e-learning. Experimental group has 28 pupils while control group has 29 pupils. The both groups belong to the same teacher. The main aim is to improve the method of mathematics lecture based on implementation of e-learning. Six inputs and one output are generated from the data as follows:

- Input 1: average mark in previous scholar year (grade V) - average mark of all subjects in one scholar year.

- Input 2: number of points on initial test (grade VI) - number of points on initial test at beginning of school year (0-100).

- Input 3: self-valuation of learning motivation from 1 up to 10 (grade VI) description of pupils' learning motivation (1 - lowest learning motivation, 10 highest learning motivation).

- Input 4: learning ration with education software and traditional learning outside regular educational process (grade VI) - ratio of number of subjects with education software (outside regular educational process) and number of subjects 
Dalibor Petković et al.

with traditional learning (outside regular educational process) - 35 subjects are used.

- Input 5: number of points on a yearly test (grade VI) - number of points on final test of a school year (0-100).

- Input 6: average mark in the end of a school year (grade VI) - average mark of all subjects during one school year (1-5).

- Output: number of points on initial test in the next school year (grade VII) number of points on initial test at beginning of school year (0-100).

Table 1. Experimental group - educational software included in learning process

\begin{tabular}{c|c|c|c|c|c|c}
\hline Input 1 & Input 2 & Input 3 & Input 4 & Input 5 & Input 6 & Output \\
\hline 3.75 & 54 & 8 & 3.29 & 68 & 3.95 & 70 \\
4.07 & 67 & 8 & 2.75 & 76 & 4.13 & 75 \\
2.93 & 41 & 7 & 2.75 & 48 & 3 & 50 \\
4.83 & 75 & 9 & 5 & 84 & 4.92 & 84 \\
2.25 & 37 & 7 & 2.33 & 44 & 2.33 & 43 \\
5 & 83 & 9 & 5 & 91 & 5 & 92 \\
1.75 & 32 & 7 & 2 & 40 & 2 & 41 \\
2.45 & 44 & 8 & 2.33 & 47 & 2.5 & 44 \\
3.5 & 51 & 9 & 2.75 & 61 & 3.5 & 60 \\
4.67 & 72 & 9 & 4 & 83 & 4.83 & 84 \\
4 & 70 & 9 & 5 & 80 & 4.07 & 79 \\
4.33 & 69 & 8 & 3.29 & 83 & 4.5 & 85 \\
4.75 & 81 & 10 & 4 & 89 & 4.92 & 86 \\
3.33 & 59 & 8 & 3.29 & 68 & 3.33 & 70 \\
2.43 & 42 & 8 & 2.75 & 50 & 2.5 & 52 \\
3 & 45 & 7 & 2.33 & 51 & 3 & 50 \\
4 & 72 & 8 & 3.29 & 78 & 4.13 & 77 \\
2 & 41 & 8 & 2.75 & 50 & 2.33 & 55 \\
2.43 & 46 & 7 & 2 & 49 & 2.5 & 50 \\
3.84 & 66 & 9 & 3.29 & 81 & 4 & 80 \\
3.24 & 65 & 10 & 2.75 & 76 & 3.33 & 75 \\
4.5 & 73 & 8 & 4 & 84 & 4.75 & 82 \\
3.2 & 50 & 7 & 4 & 62 & 3.4 & 63 \\
2.95 & 47 & 7 & 3.29 & 59 & 3 & 59 \\
3.17 & 47 & 9 & 2.75 & 61 & 3.33 & 60 \\
2.15 & 38 & 8 & 2.33 & 48 & 2.33 & 50 \\
2.47 & 37 & 7 & 2.75 & 47 & 2.64 & 45 \\
3.33 & 52 & 8 & 3.29 & 61 & 3.53 & 60 \\
\hline & & & & & & \\
\end{tabular}

Table 2. Control group - traditional learning process without educational software

\begin{tabular}{c|c|c|c|c|c|c}
\hline Input 1 & Input 2 & Input 3 & Input 4 & Input 5 & Input 6 & Output \\
\hline 4.63 & 72 & 8 & 0.36 & 81 & 4.53 & 73 \\
3.85 & 55 & 6 & 0.3 & 64 & 3.85 & 57 \\
3.34 & 54 & 5 & 0.11 & 61 & 3.33 & 56 \\
4.13 & 60 & 7 & 0.25 & 71 & 4.07 & 67 \\
2.47 & 41 & 4 & 0.15 & 49 & 2.5 & 45 \\
3.84 & 55 & 6 & 0.3 & 63 & 3.75 & 56 \\
3.5 & 49 & 6 & 0.2 & 62 & 3.64 & 55 \\
4 & 67 & 5 & 0.3 & 72 & 4.07 & 68 \\
4.75 & 79 & 7 & 0.25 & 79 & 4.64 & 78 \\
2.43 & 39 & 4 & 0.11 & 46 & 2.5 & 39 \\
2.43 & 41 & 5 & 0.07 & 45 & 2.33 & 40 \\
3.84 & 67 & 6 & 0.25 & 73 & 3.84 & 68 \\
2.95 & 51 & 5 & 0.42 & 54 & 2.64 & 52 \\
2.47 & 42 & 4 & 0.11 & 48 & 2.33 & 47 \\
3.33 & 60 & 7 & 0.15 & 62 & 3.43 & 59
\end{tabular}




\begin{tabular}{c|c|c|c|c|c|c}
5 & 88 & 9 & 0.36 & 90 & 5 & 82 \\
4.05 & 71 & 6 & 0.3 & 78 & 4 & 70 \\
4.58 & 72 & 6 & 0.25 & 79 & 4.64 & 76 \\
3.67 & 64 & 7 & 0.11 & 68 & 3.54 & 64 \\
2.13 & 36 & 4 & 0.03 & 43 & 2.2 & 40 \\
1.83 & 38 & 3 & 0 & 41 & 1.64 & 38 \\
2 & 33 & 4 & 0.07 & 41 & 2 & 36 \\
4.92 & 81 & 7 & 0.42 & 89 & 4.83 & 81 \\
4.43 & 72 & 8 & 0.42 & 79 & 4.33 & 71 \\
3 & 49 & 6 & 0.2 & 56 & 3.07 & 48 \\
3.33 & 53 & 5 & 0.25 & 59 & 3.43 & 51 \\
2.5 & 42 & 5 & 0.15 & 48 & 2.43 & 47 \\
2.45 & 42 & 4 & 0.11 & 49 & 2.5 & 46 \\
3.17 & 51 & 6 & 0.11 & 55 & 3.07 & 47 \\
\hline
\end{tabular}

One main hypothesis and two additional hypothesis are generated based on literature overview [33, 34, 35, 36, 37] and according to the current state of the educational process:

- Main hypothesis of the study: The adopted knowledge with e-learning has more continuity.

- Additional hypothesis 1: There is more motivation for learning with e-learning.

- Additional hypothesis 2: Pupils could be easily adapted to innovations in lecture.

\subsection{Computational Intelligence}

In this study adaptive neuro-fuzzy inference system (ANFIS) is used as the computational intelligence technique for the data evaluation. The methodology is capable to handle highly nonlinear data which are prone to errors. The ANFIS model represents an artificial neural network model merged with fuzzy inference system. The model has five layers. Each of the layer has different task during computational process. In the beginning of the process, the data samples with input and output variables are attached to the ANFIS model. The ANFIS are then trained by training algorithm in order to learn the knowledge from the attached data. When the ANFIS model are trained, the trained model could be used to make prediction for the unknown input variable or to rank of the input variables based on their influence on the output variable. As the main indicator for the ranking procedure root means square error (RMSE) is used.

\section{Results}

\subsection{E-learning Platform Architecture}

Almost every activity needs some kind of planning process. The planning process should improve the activity flow in order to reach the goal faster and easier than traditional process without planning. The same things happen also in learning process. Without learning planning it is more difficult to reach the learning objectives. Therefore in this study the e-learning model has the capability for planning learning paths for every learner. 
Dalibor Petković et al.

Based on the RUP methodology there is needed to identify the users of the e-learning system. The users could be divided in two main groups:

- Students,

- Teacher,

Each student should have individual username and password in order to access to the system. Teacher should perform main tasks and additional tasks. The additional tasks are important for stable operation of the e-learning system. For example teacher needs to maintain the system and learning materials to be relevant. The use case diagram of the e-learning system is shown in Figure 4. As can be seen students and teacher have several interactions through use cases. First of all the students could learn some new material by the system after logging. Teacher could only perform teaching and administrative processes which is presented as two separated use cases. These main use cases will be analyzed in more details.

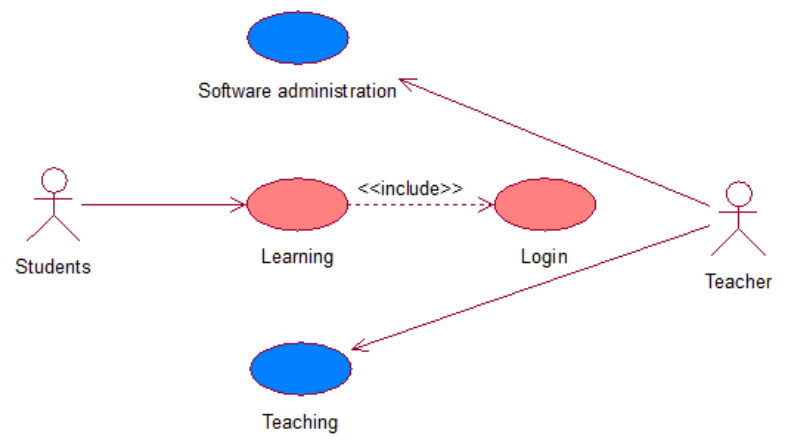

Figure 3. Main use case diagram of the e-learning system

\section{- Software administration}

Figure 4 shows use case diagram for software administration. There are two use cases in the diagram. The first use case is software maintaining and the second use case is learning material maintaining.

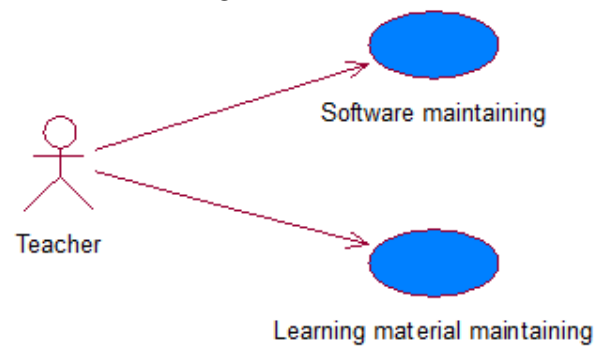

Figure 4. Use case diagram - Software administration

\section{- Learning}

Figure 5 shows use case diagram for learning process. There are six use cases in the diagram which should be achieved through the learning process by students and teacher. Students are responsible to input initial background, to input learning goals and to enroll and to execute a course. In order to achieve the tasks students need to login in the system before all. Finally students could add changes in the course based on their preconditions and preferences. Teacher is only responsible for course executing and to add potential changes in the course if students require it. Figure 6 shows the activity diagrams for activities flow of the learning process. As 
can be seen students have possibility to suggest new changes to be added in the learning process. The adding changes in learning process are not mandatory task.

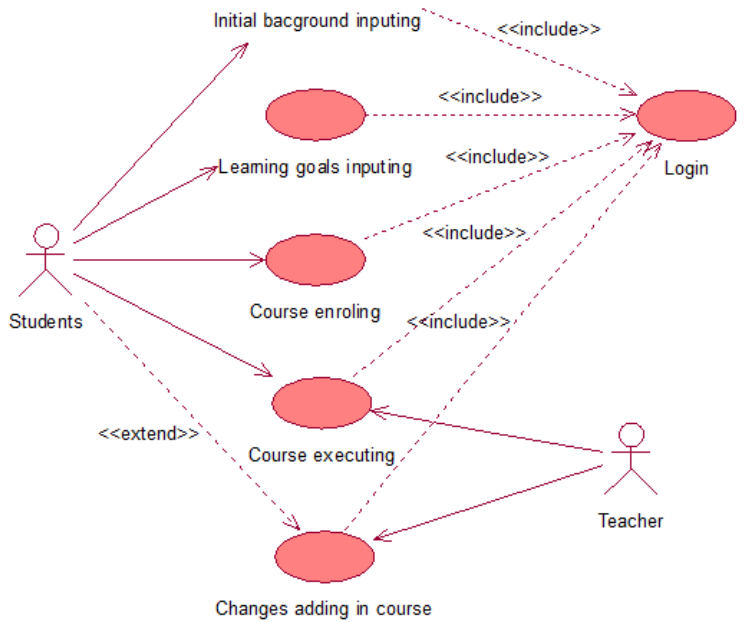

Figure 5. Use case diagram - Learning

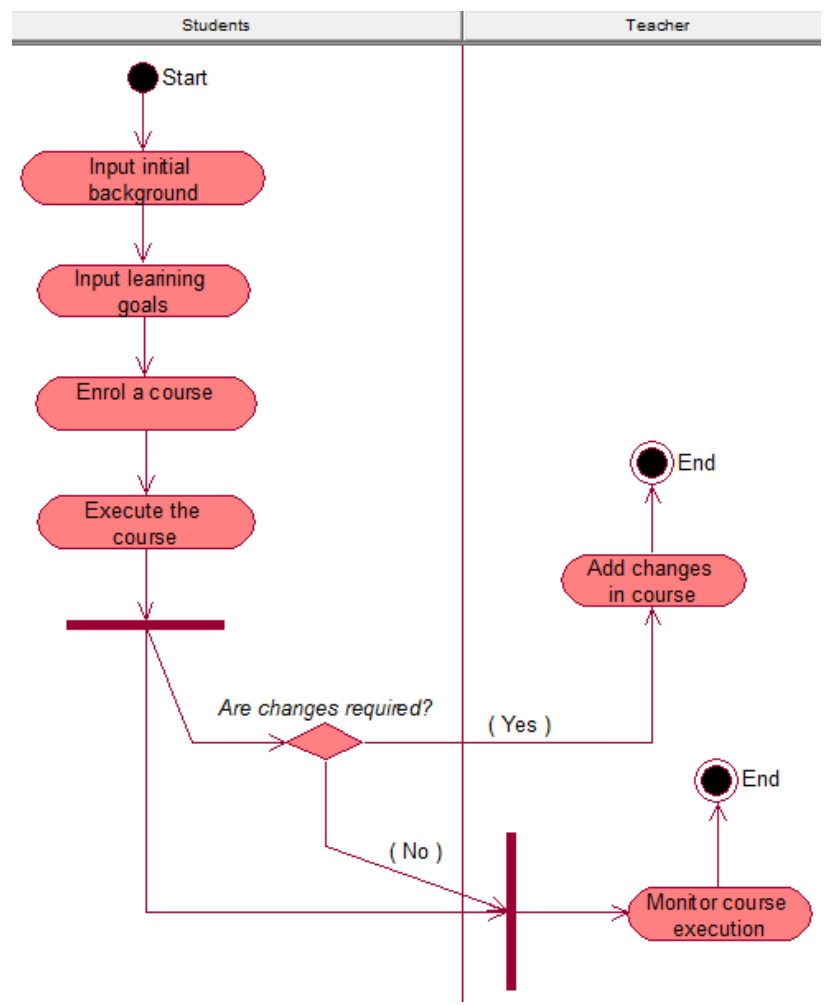

- Teaching

Figure 6. Activity diagram - Learning

Figure 7 shows use case diagram for teaching process. There are eight use cases in the diagram which should be achieved through the teaching process by students 
Dalibor Petković et al.

and teacher. Teachers are responsible for course building and for monitoring of course execution. Course building use case has several separated activities. For example teacher needs to plan the course, to plan algorithms for the course, to plan learning paths, to upload the learning paths and to visualize the learning paths. Afterwards teacher could update the learning paths for each student but it depend if students require the changes or not. Figure 8 shows the activity diagrams for activities flow of the teaching process.

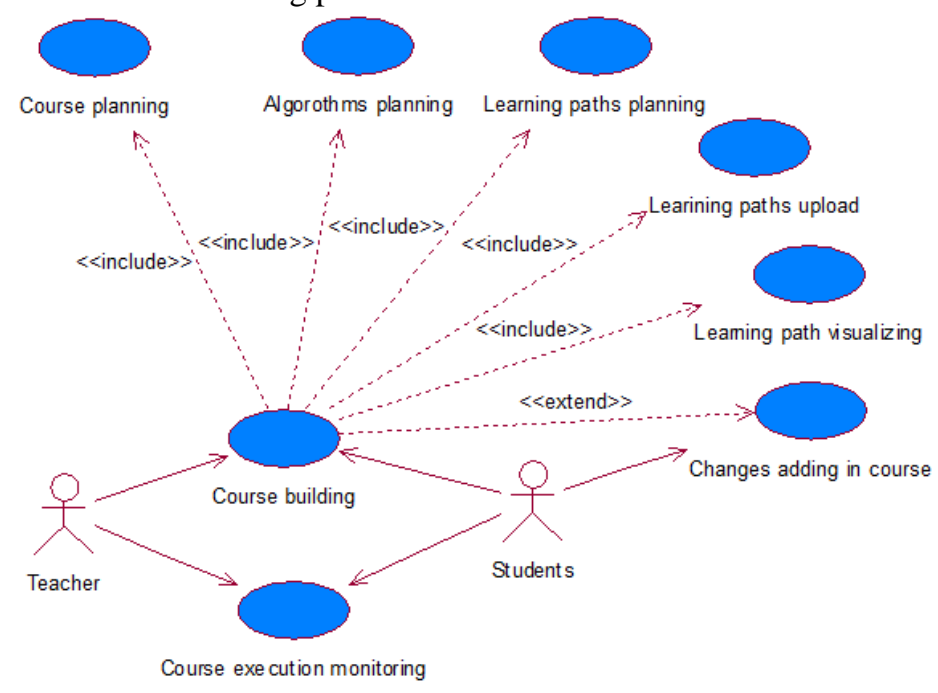

Figure 7. Use case diagram: Teaching

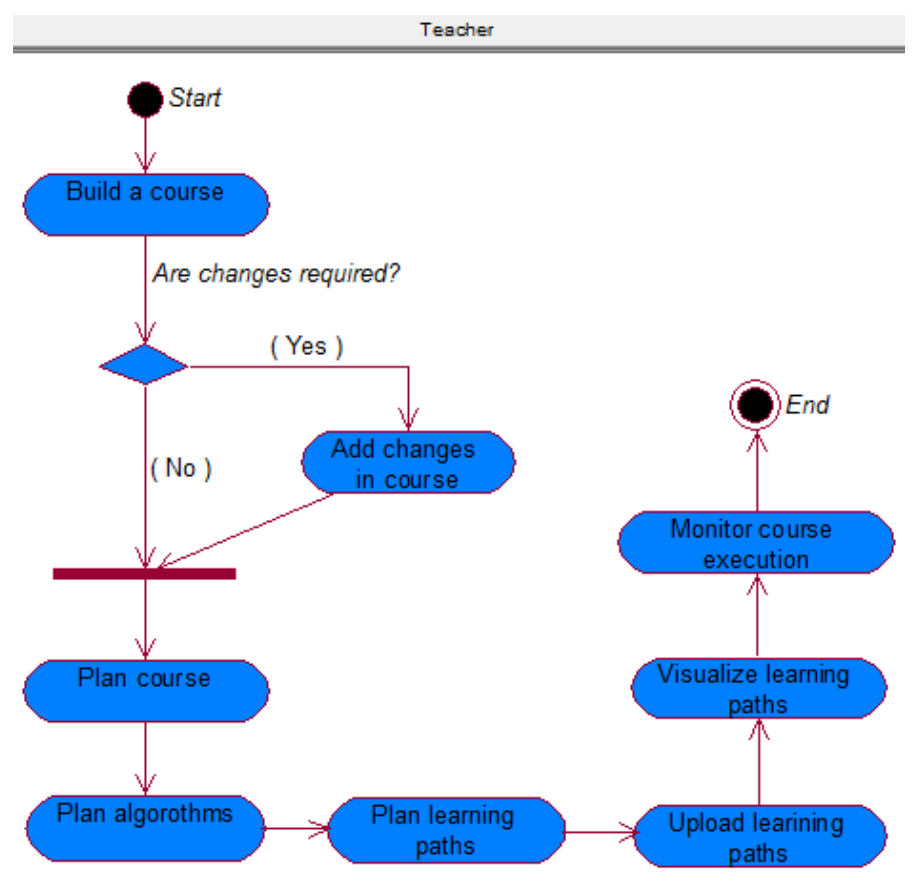

Figure 8. Activity diagram - Teaching. 


\subsection{Neuro-fuzzy Results}

In the beginning the ANFIS model is trained for single inputs in order to rank the inputs impact on the given output for the both datasets separately. The inputs RMSE values based on their influence on the output for the experimental group are given below:

- Input 1: RMSE training=4.7398, RMSE checking $=5.2702$

- Input 2: RMSE training=2.5250, RMSE checking $=4.7040$

- Input 3: RMSE training=8.2253, RMSE checking $=15.1061$

- Input 4: RMSE training=8.4628, RMSE checking $=9.2799$

- Input 5: RMSE training=1.2257, RMSE checking $=2.5282$

- Input 6: RMSE training=4.7260, RMSE checking $=5.0582$

As can be seen the input variable 5 (number of points on a yearly test (grade VI)) represents the most influential variable for the output parameter since the RMSE is minimal for the given input variable. It means the number of points on a yearly test in grade VI could has highest influence on the number of points on initial test in the grade VII for experimental group where educational software is included. Furthermore if two input variables are combined for the experimental group the following combination of the variables represent the most influential combination on the given output:

- Input 1 Input 2: RMSE training=0.9623, RMSE checking $=7.8897$

- Input 1 Input 3: RMSE training=1.6094, RMSE checking $=17.7283$

- Input 1 Input 4: RMSE training=2.4268, RMSE checking $=101.6337$

- Input 1 Input 5: RMSE training=0.3062, RMSE checking $=4.1655$

- Input 1 Input 6: RMSE training=2.9324, RMSE checking $=11.3145$

- Input 2 Input 3: RMSE training=1.3094, RMSE checking $=6.4513$

- Input 2 Input 4: RMSE training=0.6118, RMSE checking $=31.1756$ 
Dalibor Petković et al.

- Input 2 Input 5: RMSE training=0.8521, RMSE checking=3.9184

- Input 2 Input 6: RMSE training=1.0945, RMSE checking=8.9653

- Input 3 Input 4: RMSE training=2.3564, RMSE checking $=15.2188$

- Input 3 Input 5: RMSE training=0.8504, RMSE checking $=9.8933$

- Input 3 Input 6: RMSE training=1.4276, RMSE checking $=13.5554$

- Input 4 Input 5: RMSE training=0.5499, RMSE checking $=10.5291$

- Input 4 Input 6: RMSE training=3.3598, RMSE checking $=79.1869$

- Input 5 Input 6: RMSE training=0.3857, RMSE checking $=3.2565$

As can be seen the combination of input variables 1 and 5 (average mark in previous scholar year (grade V) and number of points on a yearly test (grade VI)) represents the most influential variable for the output parameter since the RMSE is minimal for the given combination. It means the average mark in grade $\mathrm{V}$ and number of points on a yearly test in grade VI could has highest influence on the number of points on initial test in the grade VII for experimental group where educational software is included.

The inputs RMSE values based on their influence on the output for the control group are given below:

- Input 1: RMSE training=2.7029, RMSE checking=4.1556

- Input 2: RMSE training=2.3939, RMSE checking=3.1989

- Input 3: RMSE training=7.7483, RMSE checking $=8.6403$

- Input 4: RMSE training=8.9772, RMSE checking $=8.7332$

- Input 5: RMSE training=2.2684, RMSE checking $=2.0222$

- Input 6: RMSE training=3.2751, RMSE checking $=4.1210$

As can be seen the input variable 5 (number of points on a yearly test (grade VI)) represents the most influential variable for the output parameter since the RMSE is minimal for the given input variable. It means the number of points on a yearly test in grade VI could has highest influence on the number of points on initial test in 
the grade VII for control group where educational software is not included. Furthermore if two input variables are combined for the control group the following combination of the variables represent the most influential combination on the given output:

- Input 1 Input 2: RMSE training=1.2998, RMSE checking $=23.2562$

- Input 1 Input 3: RMSE training=1.6405, RMSE checking $=6.6172$

- Input 1 Input 4: RMSE training=1.8749, RMSE checking $=6.2319$

- Input 1 Input 5: RMSE training=1.3697, RMSE checking $=2.3510$

- Input 1 Input 6: RMSE training=2.0556, RMSE checking $=6.8113$

- Input 2 Input 3: RMSE training=1.7125, RMSE checking $=21.8479$

- Input 2 Input 4: RMSE training=1.7029, RMSE checking $=7.4871$

- Input 2 Input 5: RMSE training=1.1756, RMSE checking $=8.7239$

- Input 2 Input 6: RMSE training=1.3704, RMSE checking $=6.9615$

- Input 3 Input 4: RMSE training=1.5706, RMSE checking $=39.6118$

- Input 3 Input 5: RMSE training=0.6979, RMSE checking $=19.6465$

- Input 3 Input 6: RMSE training=0.7022, RMSE checking $=51.9284$

- Input 4 Input 5: RMSE training=0.4713, RMSE checking $=7.6132$

- Input 4 Input 6: RMSE training=1.4699, RMSE checking=7.7761

- Input 5 Input 6: RMSE training=0.8823, RMSE checking $=1.6264$

As can be seen the combination of input variables 4 and 5 (learning ration with education software and traditional learning outside regular educational process (grade VI) and number of points on a yearly test (grade VI)) represents the most influential variable for the output parameter since the RMSE is minimal for the given combination. It means the learning ration with education software and traditional learning outside regular educational process in grade VI and number of points on a yearly test in grade VI could has highest influence on the number of points on initial test in the grade VII for control group where educational software 
is not included.

\section{Conclusion}

Unified modelling language (UML) was used as tool for the modelling purpose of the system. UML is suitable for the modeling process since the system is visualized and graphically presented for easy understanding of the process in the system. The main advantage of the e-learning system is its adaptability based on learners' preferences and background. In other words every learner could have different learning paths and accordingly different learning material.

\section{Conflicts of Interest}

There is no conflict of interest.

\section{References}

[1] Chen, W., Mason, S., Staniszewski, C., Upton, A., \& Valley, M. (2012). Assessing the quality of teachers' teaching practices. Educational Assessment, Evaluation and Accountability, 24(1), 25-41.

[2] Chowdhury, H., Alam, F., \& Mustary, I. (2019). Development of an innovative technique for teaching and learning of laboratory experiments for engineering courses. Energy Procedia, 160, 806-811.

[3] Oproiu, G. C. (2015). A study about using e-learning platform (Moodle) in university teaching process. Procedia-Social and Behavioral Sciences, 180, 426-432.

[4] Wilson, R. (2014). Student absences and student abscesses: Impediments to quality teaching. The Urban Review, 46(5), 831-845.

[5] Rutland, M., \& Barlex, D. (2008). Perspectives on pupil creativity in design and technology in the lower secondary curriculum in England. International Journal of Technology and Design Education, 18(2), 139-165.

[6] Glendinning, S. (2017). A new rootedness? education in the technological age. Studies in Philosophy and Education, 1-16.

[7] Eyles, A., Hupkau, C., \& Machin, S. (2016). School reforms and pupil performance. Labour Economics, 41, 9-19.

[8] Kazarina, L., Khasanshin, Y., \& Smyshlyaeva, L. (2015). Teaching Model of Pupils' Research Competence Formation in the Context of Humanitarian Subject-oriented Classes of General Education School: Functional and Organizational Characteristics. Procedia-Social and Behavioral Sciences, 206, 241-246.

[9] Maietta, O. W., \& Gorgitano, M. T. (2016). School meals and pupil satisfaction. Evidence from Italian primary schools. Food Policy, 62, 41-55.

[10] Bartholomew, K. J., Ntoumanis, N., Mouratidis, A., Katartzi, E., Thøgersen-Ntoumani, C., \& Vlachopoulos, S. (2018). Beware of your teaching style: A school-year long investigation of controlling teaching and student motivational experiences. Learning and Instruction, 53, 50-63. 
[11] Mulera, D. M. W., Ndala, K. K., \& Nyirongo, R. (2017). Analysis of factors affecting pupil performance in Malawi's primary schools based on SACMEQ survey results. International Journal of Educational Development, 54, 59-68.

[12] Salleh, N. M., \& Aiman, M. S. (2015). Improving The Quality Of Pupils' Response In Science Inquiry Teaching: A Participatory Action Research. Procedia-Social and Behavioral Sciences, 191, 1310-1316.

[13] Singh, R., \& Sarkar, S. (2015). Does teaching quality matter? Students learning outcome related to teaching quality in public and private primary schools in India. International Journal of Educational Development, 41, 153-163.

[14] Mattar, D. M. (2012). Factors affecting the performance of public schools in Lebanon. International Journal of Educational Development, 32(2), 252-263.

[15] Giannakos, M. N. (2013). Enjoy and learn with educational games: Examining factors affecting learning performance. Computers \& Education, 68, 429-439.

[16] Galbraith, P. L. (1986). The use of mathematical strategies: Factors and features affecting performance. Educational Studies in Mathematics, 17(4), 413-441.

[17] Hungi, N., \& Postlethwaite, N. T. (2009). The key factors affecting Grade 5 achievement in Laos: emerging policy issues. Educational Research for Policy and Practice, 8(3), 211-230.

[18] Ortega-Morán, J. F., Pagador, J. B., Sánchez-Peralta, L. F., Sánchez-González, P., Noguera, J., Burgos, D., \& Sánchez-Margallo, F. M. (2017). Validation of the three web quality dimensions of a minimally invasive surgery e-learning platform. International journal of medical informatics, 107, 1-10.

[19] Roskos, K., Brueck, J., \& Lenhart, L. (2017). An analysis of e-book learning platforms: Affordances, architecture, functionality and analytics. International Journal of Child-Computer Interaction, 12, 37-45.

[20] Fenu, G., Marras, M., \& Boratto, L. (2017). A multi-biometric system for continuous student authentication in e-learning platforms. Pattern Recognition Letters.

[21] Benta, D., Bologa, G., \& Dzitac, I. (2014). E-learning platforms in higher education. case study. Procedia Computer Science, 31, 1170-1176.

[22] Benta, D., Bologa, G., Dzitac, S., \& Dzitac, I. (2015). University level learning and teaching via e-learning platforms. Procedia Computer Science, 55, 1366-1373.

[23] Oproiu, G. C. (2015). A study about using e-learning platform (Moodle) in university teaching process. Procedia-Social and Behavioral Sciences, 180, 426-432.

[24] Dodun, O., Panaite, E., Seghedin, N., Nagîț, G., Duşa, P., Neştian, G., \& Slătineanu, L. (2015). Analysis of an E-learning Platform use by Means of the Axiomatic Design. Procedia CIRP, 34, 244-249.

[25] Luminita, D. C. (2011). Information security in E-learning Platforms. Procedia-Social and Behavioral Sciences, 15, 2689-2693.

[26] Srivastava, B., \& Haider, M. T. U. (2017). Personalized assessment model for alphabets learning with learning objects in e-learning environment for 
Dalibor Petković et al.

dyslexia. Journal of King Saud University-Computer and Information Sciences.

[27] Tsolis, D., Stamou, S., Christia, P., Kampana, S., Rapakoulia, T., Skouta, M., \& Tsakalidis, A. (2010). An adaptive and personalized open source e-learning platform. Procedia-Social and Behavioral Sciences, 9, 38-43.

[28] Lethbridge, T. C., \& Laganiere, R. (2005). Object-oriented software engineering. New York: McGraw-Hill.

[29] Jacobson, I. (1993). Object-oriented software engineering: a use case driven approach. Pearson Education India.

[30] Rumbaugh, J., Jacobson, I., \& Booch, G. (2004). Unified modeling language reference manual, the. Pearson Higher Education.

[31] Jang, J.-S.R, ANFIS: Adaptive-Network-based Fuzzy Inference Systems, IEEE Trans. On Systems, Man, and Cybernetics (1993), Vol.23, 665-685.

[32] Process, R. U. (2001). Best practices for software development teams. A Rational Software Corporation White Paper. Recuperado de: https://www. ibm.

com/developerworks/rational/library/content/03July/1000/1251/1251_bestpra ctices_TP026B.pdf.

[33] Wang, H., \& Zhang, B. (2019). Teaching a generative model: Mathematical formulation and solution framework. Computers \& Industrial Engineering, 130, 119-126.

[34] Saadon, S., Rambely, A. S., \& Suradi, N. R. M. (2011). The role of computer labs in teaching and learning process in the field of Mathematical Sciences. Procedia-Social and Behavioral Sciences, 18, 348-352.

[35] Spinczyk, D., Maćkowski, M., Kempa, W., \& Rojewska, K. (2019). Factors influencing the process of learning mathematics among visually impaired and blind people. Computers in biology and medicine, 104, 1-9.

[36] Zou, F., Chen, D., \& Xu, Q. (2019). A survey of teaching-learning-based optimization. Neurocomputing, 335, 366-383.

[37] Xu, Y., Yang, Z., Li, X., Kang, H., \& Yang, X. (2019). Dynamic opposite learning enhanced teaching-learning-based optimization. Knowledge-Based Systems, 104966. 